\title{
Preliminary Examination of the System Fly Ash-Bottom Ash-Flue Gas Desulphurization Gypsum-Portland Cement-Water for Road Construction
}

\author{
R. Tokalic, ${ }^{1}$ S. Marinkovic, ${ }^{1}$ P. Trifunovic, ${ }^{1}$ G. Devic, ${ }^{2}$ and S. Zildzovic ${ }^{3}$ \\ ${ }^{1}$ Faculty of Mining and Geology, University of Belgrade, Djusina 7, 11000 Belgrade, Serbia \\ ${ }^{2}$ Department of Chemistry, IHTM Njegoseva 12, 11000 Belgrade, Serbia \\ ${ }^{3}$ Institute for the Technology of Nuclear and Other Raw Materials, Franse d Eperea 86, 11000 Belgrade, Serbia \\ Correspondence should be addressed to R. Tokalic; tokalic@rgf.bg.ac.rs
}

Received 21 June 2012; Revised 26 September 2012; Accepted 10 October 2012

Academic Editor: Saima Q. Memon

Copyright (c) 2013 R. Tokalic et al. This is an open access article distributed under the Creative Commons Attribution License, which permits unrestricted use, distribution, and reproduction in any medium, provided the original work is properly cited.

This paper describes an investigation into the use of three power plant wastes: fly ash, flue gas desulphurization gypsum, and bottom ash for subbase layers in road construction. Two kinds of mixtures of these wastes with Portland cement and water were made: first with fly ash consisting of coarser particles $(<1.651 \mathrm{~mm})$ and second with fly ash consisting of smaller particles $(<0.42 \mathrm{~mm})$. The mass ratio of fly ash-Portland cement-flue gas desulphurization gypsum-bottom ash was the same $(3: 1: 1: 5)$ in both mixtures. For both mixtures, the compressive strength, the mineralogical composition, and the leaching characteristics were determined at different times, 7 and 28 days, after preparation. The obtained results showed that both mixtures could find a potential use for subbase layers in road construction.

\section{Introduction}

Fly ash (FA), bottom ash (BA), and flue gas desulphurization wastes (FGD gypsum) are three byproducts, that is, wastes, from power plants. The disposal of these wastes is an economic problem and an ecological problem (pollution of air, waters, and soil), and consequently there is intensive search to increase the use of these wastes as construction materials, especially if they are used in bulk (in the large volume building material industry, in civil engineering).

The application of wastes from power plants (FA, BA, and FGD gypsum) as construction materials is connected with their characteristics.

FA with a low $\mathrm{CaO}$ content (class $\mathrm{F}$ according to ASTM 618) may exhibit pozzolanic properties (itself possessing little or no cementing value, but, in the presence of moisture, it reacts chemically with calcium hydroxide at ambient temperature to form compounds that possess cementing properties) and could be applied as a substitute for Portland cement (PC) in concrete [1-5]. FA with a high $\mathrm{CaO}$ content (class $\mathrm{C}$, according to ASTM 618) has alone hardening properties in the presence of moisture, without the addition of calcium hydroxide [1].

$\mathrm{BA}$ is a more or less inert material; that is; bottom ash usually does not exhibit pozzolanic properties, but it could be a potential aggregate in concrete as a replacement for natural sand (its particles are coarse, sized between sand and gravel, fused, and with a glassy texture) $[2,6,7]$.

FGD gypsum could be applied as chemical activator of FA in FA/cement system, based on the ability of gypsum to react with aluminium oxide in the glass phase of fly ash to produce ettringite that contributes to the strength in the early ages [8].

Fly ash from Serbian power plant "Nicola Tesla" (class F) is a powdered material consisting of small particles $(<1.651 \mathrm{~mm})$ with good pozzolanic properties, which means that it is a reactive material with potential suitability for use as a replacement for Portland cement.

Flue gas desulphurisation gypsum from the Bohemian Power Plant (Hvaletice) is a powdered material (its particles are smaller than $0.104 \mathrm{~mm}$ ), mainly composed of $\mathrm{CaSO}_{4} \cdot 2 \mathrm{H}_{2} \mathrm{O}$, with potential use as an $\mathrm{FA}$ activator. 
Bottom ash from the Serbian power plant "Nicola Tesla" has a lower quality (high loss on ignition, low density, low bulk density, and low compactability) than natural aggregates (sand and gravel) and as such, has the potential for use as road subbases, when the strength requirements are not very high.

The aim of this work was to investigate the possibilities of the potential utilisation of FA and BA from the Serbian power plant "Nicola Tesla" and FGD gypsum from the Bohemian Power Plant-Hvaletice (no Serbian plant has an FGD system installed yet) for subbase layers in road construction.

Due to the promised properties (good reactivity) of FA and FGD gypsum (exposed above) and for economic and ecological reasons (recycling of waste materials and avoidance of the necessity of their disposal), two mixtures with a low content of Portland cement and a high content of power plant wastes (FA, FGD gypsum, and BA) were prepared. These mixtures had the same mass composition (FA : PC:FGD gypsum : $\mathrm{BA}=3: 1: 1: 5$ ), but they were different in terms of the size of the FA particles. For both mixtures, the compressive strength, mineralogical composition, and leaching characteristics were determined 7 and 28 days after preparation. These properties are of primary importance for a preliminary examination and assessment for any possible application of the materials in construction.

The compressive strength is an essential parameter for mechanical characterization and indicator of the overall quality of cement materials. The mineralogical composition and leaching characteristics are very important properties for an assessment of the applicability of materials for construction. The mineralogical composition influences the compressive strength and durability of materials. The leaching characteristics predict the environmental impact of the materials.

\section{Experimental}

First, the chemical properties (chemical composition and mineralogical composition) of the materials (FA, BA, and FGD gypsum) were investigated. Then, the compressive strength, mineralogical composition, and leaching behaviour of mixtures made from these materials and Portland cement (PC) and water (W) were determined.

The chemical compositions of materials (presented as oxide equivalents) were determined by classic chemical analysis.

The mineralogical compositions of FA and BA were determined by the powder XRD technique using a Philips PW 1729 X-ray generator and a Philips PW 1710 diffractometer. The radiation source was an X-ray LLF tube with copper radiation and a graphite monochromator. The radiation wavelength $\lambda_{\mathrm{CuK} \alpha 1}$ was $0.15405 \mathrm{~nm}$. The anode tube load was $40 \mathrm{KV}$ and $30 \mathrm{~mA}$. The samples were pressed into standard aluminium frames and measured in the $2 \theta$ range from $5^{\circ}$ to $50^{\circ}$. The recorded data were interpreted using JCPDS cards.

FGD gypsum was examined by qualitative IR analysis. The IR absorption spectrum of FGD gypsum was recorded on a Perkin Elmer 782 spectrophotometer in the range from 4000 to $400 \mathrm{~cm}^{-1}$, using the $\mathrm{KBr}$ pressed disc technique.
The mixtures (pastes) fly ash-Portland cement-flue gas desulphurization gypsum-bottom ash-water (FA-PC-FGD gypsum-BA-W) were made using (1) raw fly ash (consisting of particles smaller than $1.651 \mathrm{~mm}$ ) and (2) sieved fly ash (consisting of particles smaller than $0.42 \mathrm{~mm}$ ). The mass ratio of solid materials in these mixtures was the same (FA : PC : FGD gypsum : $\mathrm{BA}=3: 1: 1: 5$ ).

To simulate a stabilization (necessary for the use of the mixtures in road construction) cylindrical specimens (diameter $10.2 \mathrm{~cm}$ and height $11.7 \mathrm{~cm}$ ), so-called Proctor specimens, of both mixtures with the optimum moisture content were made by compaction. The values of the optimum moisture content for both mixtures (FA:PC:FGD gypsum: $\mathrm{BA}=3: 1: 1: 5)$ with $\mathrm{FA}$ of different particle size (smaller than $1.651 \mathrm{~mm}$ and smaller than $0.42 \mathrm{~mm}$ ) were determined by the Standard Proctor test (ASTM D698). These values were practically the same and about $38 \%$.

Consequently, the mass composition of both mixtures was $18.6 \%$ FA-6.2\% PC-6.2\% FGD gypsum-31\% BA-38\% W.

Six Proctor specimens of these mixtures were stored for 7 days, and another six of one were stored for 28 days in a humid room $\left(20 \pm 2^{\circ} \mathrm{C}, 85 \%\right.$ humidity). After storage, the following properties of the specimens were determined: compressive strength, mineralogical composition, leaching behaviour, water content, and absorption of water.

The compressive strength was determined according to the Serbian Standard SRPS U.B1.030 (which is in accordance with European Standard EN 14227-4).

The values of compressive strength given in this work present an average value of the compressive strength of three specimens of both hardening mixtures after 7 and 28 days.

Determination of mineralogical composition and leaching behaviour were performed with pulverized crushed (during the determination of their compressive strength) samples. The mineralogical composition of the samples was examined in the same manner as for FA and BA (described above).

The leaching behaviour of specimens was determined according to the method described in European Standard EN 12457. This method consists of placing $100 \mathrm{~g}$ of pulverised material in $1000 \mathrm{~cm}^{3}$ of distilled water, agitating for $24 \mathrm{~h}$ $(5 \mathrm{rpm})$ and then filtering the material-water suspension. In the present study, tap water was used as the liquid medium $(\mathrm{pH}=6)$ instead of distilled water. The liquid phase (extract) was analyzed by atomic absorption spectroscopy (Perkin Elmer "Analyst 300" spectrophotometer). The measurements were performed in an air/acetylene flame and an $\mathrm{N}_{2} \mathrm{O}$ /acetylene flame. External standard solutions were prepared from $1000 \mathrm{mg} / \mathrm{dm}^{3}$ stock metal solutions. The results of leaching test were compared with waste acceptance criteria (WAC) for granular wastes (limit values for the compliance test using EN 12457 at L/S = 10).

Water content and absorption of water of monolithic (noncrushed) cylindrical (Proctor) specimens were determined according to SRPS U.B1.012 and SRPS B.B8.010., respectively. Three specimens of both mixtures after 7 and 28 days were dried to constant mass at $85^{\circ} \mathrm{C}$. Based on the masses of the wet and dry specimens, the water content was calculated in \% (as mean value of three measurements). 
Subsequently, the same dry specimens were immersed in tap water for $24 \mathrm{~h}$. The water absorption (average value in \%) was calculated using the masses of the specimens after and before immersion in water.

\section{Results and Discussion}

The content of main component (presented as oxide equivalents) of the materials is given in Table 1.

Based on the chemical analysis results, it is evident that the fly ash from the Nicola Tesla Power Plant could be classified as a low calcium fly ash (class F, according to ASTM 618). It satisfies ASTM C618 Standard specification for use as a pozzolan for replacement of Portland cement in concrete because its FAS content $\left(\mathrm{Fe}_{2} \mathrm{O}_{3}+\mathrm{Al}_{2} \mathrm{O}_{3}+\mathrm{SiO}_{2}\right)$ was greater (80.66\%) than that required by ASTM 618 (70\%). In addition, the contents of $\mathrm{SO}_{3}(2.74 \%)$ and $\mathrm{Na}_{2} \mathrm{O}(0.41 \%)$, as well as the loss on ignition $(1.85 \%)$ were lower than the allowed maximum values proposed by ASTM $618(5 \%, 1.5 \%$, and $6 \%$, resp.) for the utilization of $\mathrm{FA}$ as a pozzolan.

The content of oxides: $\mathrm{SiO}_{2}, \mathrm{Al}_{2} \mathrm{O}_{3}$, and $\mathrm{Fe}_{2} \mathrm{O}_{3}$ (49.39\%, $19.70 \%$, and $5.83 \%$, resp.) was lower but the loss on ignition was higher $(8.91 \%)$ in the bottom ash than in the fly ash.

Based on the results of the chemical analysis of the FGD gypsum from the Power Plant "Hvaletice," it is evident that it was a sufficiently pure substance $\left(32.80 \% \mathrm{CaO}, 45.72 \% \mathrm{SO}_{3}\right.$, $17.18 \%$ crystal water, and $4.3 \%$ impurities).

Based on the X-ray diffraction study, it could be stated that the major crystalline phase in the fly ash was quartz$\mathrm{SiO}_{2}$. The other crystalline phases present in small amounts in the fly ash were mullite, $\mathrm{Al}_{6} \mathrm{Si}_{2} \mathrm{O}_{13}$, anhydrite, $\mathrm{CaSO}_{4}$, feldspar, $\mathrm{NaAlSi}_{3} \mathrm{O}_{8}$, diopside, $\mathrm{CaMgSi}_{2} \mathrm{O}_{6}$, hematite- $\mathrm{Fe}_{2} \mathrm{O}_{3}$, and gehlenite- $\mathrm{Ca}_{2} \mathrm{Si}_{2} \mathrm{O}_{7}$.

The major crystalline phase in the bottom ash was quartz, then calcite, $\mathrm{CaCO}_{3}$, and small amounts of anhydrite, feldspar, diopside, and hematite. In addition to the mentioned crystalline phases, a significant amount of amorphous aluminosilicates (glass) was evidenced by the broad "hump" (between $2 \theta=20^{\circ}$ and $2 \theta=30^{\circ}$ ) in the XRD diffractogram of the fly ash and bottom ash. The $\mathrm{SiO}_{2}$, present as quartz or in the crystalline aluminosilicates phase, is inert. Similarly, the part of the alumina in the crystalline phase is inactive. Both the silica and alumina in the amorphous aluminosilicates (glass) are reactive [9].

The IR spectrum of the FGD gypsum exhibited absorption bands at 3560,3420,1680,1625,1160,1120,670, and $600 \mathrm{~cm}^{-1}$, which are characteristic for $\mathrm{CaSO}_{4} \cdot 2 \mathrm{H}_{2} \mathrm{O}$, that is, gypsum [10]. In addition to these bands, the IR spectrum showed a weak absorption band at $1450 \mathrm{~cm}^{-1}$, which confirmed the presence of carbonates [10], as impurities, in the FGD gypsum.

The results presented in Table 2 are the average value of three determinations of the compressive strength of the specimens $\mathrm{S}_{1}$ (18.6\% FA, 6.2\% PC, 6.2\% FGD gypsum, 31\% $\mathrm{BA}$, and $38 \% \mathrm{~W}$, the FA consisted of particles smaller than $1.651 \mathrm{~mm})$ and $\mathrm{S}_{2}$ (18.6\% FA, 6.2\% PC, 6.2\% FGD gypsum, $31 \% \mathrm{BA}$, and $38 \% \mathrm{~W}$, the FA consisted of particles smaller than $0.42 \mathrm{~mm}$ ) after 7 and 28 days. The estimated standard deviation for the compressive strength is also given in Table 2.

The low values of standard deviations for the compressive strength of both samples (after 7 and 28 days) show that there was no spread of the obtained compressive strength results.

The results in Table 2 show that the values of the compressive strength of the specimens were relatively low. The specimen $\mathrm{S}_{2}$ (made with FA consisting of smaller particles) had greater compressive strength values than the specimen $\mathrm{S}_{1}$, both after 7 and 28 days of hardening (by 6.5 and 3.9\%, resp.). The reason for this is, probably, the higher reactivity of the smaller particles and consequently higher content of the products of hydration reactions (it is known that the compressive strength is in a functional relation with the content of the products of hydration reactions (12); the higher is their content, the greater is the compressive strength). Moreover, it is evident that the compressive strengths of both samples $\left(\mathrm{S}_{1}\right.$ and $\left.\mathrm{S}_{2}\right)$ after 28 days were considerable higher than those after 7 days (by about two times).

For the assessment of the validity of the obtained results for compressive strength of the specimens $S_{1}$ and $S_{2}$, they were compared with the criteria for compressive strength of subbase layers proposed by the Public Enterprise-Roads of Serbia (Table 3).

Comparing the obtained results (Table 2) with the criteria in Table 3, it could be concluded that both mixtures prepared in this study were suitable as a subbase only for heavy and medium traffic load.

The XRD diffractograms of the specimens after 7 and 28 days of hardening are presented in Figure 1.

The diffractograms were interpreted by means of JCPDS cards. Based on this interpretation, it could be stated that all specimens contained the same crystalline phases: quartz $\left(d=0.4257 \mathrm{~nm}, 2 \theta=20.85^{\circ} ; d=0.3342 \mathrm{~nm}, 2 \theta=26.65^{\circ}\right)$, mullite $\left(d=0.3428 \mathrm{~nm}, 2 \theta=25.97^{\circ} ; d=0.3390 \mathrm{~nm}\right.$, $\left.2 \theta=26.27^{\circ}\right)$, feldspar $\left(d=0.4020 \mathrm{~nm}, 2 \theta=22.09^{\circ} ; d=\right.$ $\left.0,318 \mathrm{~nm}, 2 \theta=28.04^{\circ}\right)$, ettringite $(d=0.9650 \mathrm{~nm}, 2 \theta=$ $\left.9.16^{\circ} ; d=0.5580 \mathrm{~nm}, 2 \theta=15.87^{\circ}\right)$, gypsum $(d=0.7630 \mathrm{~nm}$, $2 \theta=11.59^{\circ} ; d=0.4280 \mathrm{~nm}, 2 \theta=20.74^{\circ} ; d=0.3070 \mathrm{~nm}$, $\left.2 \theta=29.06^{\circ}\right)$, and calcite $\left(d=0.3035 \mathrm{~nm}, 2 \theta=29.40^{\circ}\right.$; $\left.d=0.2285 \mathrm{~nm}, 2 \theta=39.40^{\circ} ; d=0.2095 \mathrm{~nm}, 2 \theta=43.14^{\circ}\right)$.

In the diffractograms of all specimens (Figure 1), the presence of a broad hump between $2 \theta=20-38^{\circ}$ could be attributed to the presence of an amorphous $\mathrm{C}-\mathrm{S}-\mathrm{H}$ phase [11].

Quartz, mullite, and feldspar, detected in all specimens, are inherent to fly ash and bottom ash. They are inert and did not participate in the reactions occurring in the system FA-PC-FGD gypsum-BA-W. Ettringite and $\mathrm{C}-\mathrm{S}-\mathrm{H}$ are the products of the hydration reactions that occurred. Ettringite is formed by reaction between calcium aluminate, from Portland cement and FA, and gypsum from FGD gypsum and Portland cement (a small amount of gypsum is present in Portland cement).

The reaction of ettringite formation can be written as [12]

$$
\begin{array}{r}
3 \mathrm{CaO} \cdot \mathrm{Al}_{2} \mathrm{O}_{3}+3 \mathrm{CaSO}_{4} \cdot 2 \mathrm{H}_{2} \mathrm{O}+26 \mathrm{H}_{2} \mathrm{O} \\
\longrightarrow 3 \mathrm{CaO} \cdot \mathrm{Al}_{2} \mathrm{O}_{3} \cdot 3 \mathrm{CaSO}_{4} \cdot 32 \mathrm{H}_{2} \mathrm{O}
\end{array}
$$


TABLE 1: Chemical compositions of the materials.

\begin{tabular}{lcccc}
\hline Component & FA (\%) & BA (\%) & FGD gypsum (\%) & PC (\%) \\
\hline $\mathrm{SiO}_{2}$ & 52.27 & 43.39 & 0.63 & 0.14 \\
$\mathrm{Al}_{2} \mathrm{O}_{3}$ & 22.34 & 15.70 & 0.38 & 3.87 \\
$\mathrm{Fe}_{2} \mathrm{O}_{3}$ & 6.05 & 5.83 & 32.80 & 3.25 \\
$\mathrm{CaO}$ & 6.64 & 2.64 & 2.18 & 64.37 \\
$\mathrm{MgO}$ & 4.41 & 3.69 & 45.72 & 1.43 \\
$\mathrm{SO}_{3}$ & 2.74 & 1.98 & - & 1.98 \\
$\mathrm{Na}_{2} \mathrm{O}$ & 0.41 & 0.33 & - & 0.21 \\
$\mathrm{~K}_{2} \mathrm{O}$ & 1.36 & 1.02 & 1.16 & 0.63 \\
Loss on ignition & 1.85 & 8.91 & 17.18 & 1.00 \\
Crystal water & - & - & & - \\
\hline
\end{tabular}

TABLE 2: Compressive strength results for hardened specimens.

\begin{tabular}{lcccc}
\hline \multirow{2}{*}{ Specimen } & \multicolumn{2}{c}{ Compressive strength $(\mathrm{MPa})$} & \multicolumn{2}{c}{ Standard deviation $(\mathrm{MPa})$} \\
& 7 days & 28 days & 7 days & 0.2838 \\
$\mathrm{~S}_{1}$ & 1.5041 & 3.1255 & 0.0160 & 0.2238 \\
$\mathrm{~S}_{2}$ & 1.6021 & 3.2468 & 0.0437 & days \\
\hline
\end{tabular}

TABLE 3: Compressive strength of cement-stabilized mixture for subbase layers.

\begin{tabular}{lcc}
\hline Layer & \multicolumn{2}{c}{ Compressive strength (MPa) } \\
& 7 days & 28 days \\
\hline $\begin{array}{l}\text { Subbase for motorways and } \\
\text { very heavy traffic load }\end{array}$ & $2-5.5$ & $3.0-6$ \\
$\begin{array}{l}\text { Subbase for heavy and } \\
\text { medium traffic load }\end{array}$ & $1.5-5.5$ & $2.5-6$ \\
& & \\
\hline
\end{tabular}

$\mathrm{C}-\mathrm{S}-\mathrm{H}$ is the product of reactions between tricalcium silicate $\left(\mathrm{C}_{3} \mathrm{~S}\right)$ and dicalcium silicate $\left(\mathrm{C}_{2} \mathrm{~S}\right)$, from Portland cement, and water, formed according to

$$
\begin{aligned}
& \text { Portland cement }\left(\mathrm{C}_{3} \mathrm{~S}, \mathrm{C}_{2} \mathrm{~S}\right)+\mathrm{H}_{2} \mathrm{O} \\
& \longrightarrow \mathrm{C}-\mathrm{S}-\mathrm{H}+\mathrm{Ca}(\mathrm{OH})_{2}
\end{aligned}
$$

The liberated $\mathrm{Ca}(\mathrm{OH})_{2}$ from reaction (2) could react with active silicates from fly ash (present in the amorphous phase of FA) forming thereby also calcium silicate hydrate (C-S-H).

The gypsum phase was present in all the specimens despite it is being a reactant in reaction (1); its quantity was even greater in the specimens after 28 days than in the specimens after 7 days (compare the peak intensities at $d=$ $0.7630 \mathrm{~nm}$ and $2 \theta=11.59^{\circ}$ in Figure 1 ; the peak at $d=$ 0.4280 , and $2 \theta=20.74^{\circ}$ is not convenient for comparison because it overlaps with that of quartz at $d=0.4257 \mathrm{~nm}$ and $2 \theta=20.85^{\circ}$ ). In this way, it could be concluded that gypsum was formed in the specimens as a new (secondary) phase during carbonation of the specimens, via reaction with atmospheric $\mathrm{CO}_{2}$ [13], according to the following equation [14]:

$$
\begin{aligned}
& 3 \mathrm{CaO} \cdot \mathrm{Al}_{2} \mathrm{O}_{3} \cdot 3 \mathrm{CaSO}_{4} \cdot 32 \mathrm{H}_{2} \mathrm{O}+3 \mathrm{CO}_{2} \\
& \longrightarrow 3 \mathrm{CaCO}_{3}+3 \mathrm{CaSO}_{4} \cdot 2 \mathrm{H}_{2} \mathrm{O} \\
&+\mathrm{Al}_{2} \mathrm{O}_{3} \cdot n \mathrm{H}_{2} \mathrm{O}(\mathrm{gel})+(26-n) \mathrm{H}_{2} \mathrm{O}
\end{aligned}
$$

(Some amount of the gypsum in the specimens may have originated from the FGD gypsum that did not react in the hydration reactions (1)).

Carbonation of the other product of hydration reaction, that is, $\mathrm{C}-\mathrm{S}-\mathrm{H}$, very probably occurred, following the equation $[14,15]$ :

$$
\mathrm{C}_{x} \mathrm{SH}_{y}+z \mathrm{CO}_{2} \longrightarrow \mathrm{C}_{x-z} \mathrm{SH}_{y}+z \mathrm{CaCO}_{3} .
$$

Carbonation of the specimens could be confirmed by comparing the main peaks intensities of ettringite at $0.9650 \mathrm{~nm}\left(2 \theta=9.16^{\circ}\right)$, and, gypsum at $0.7630 \mathrm{~nm}(2 \theta=$ $\left.11.59^{\circ}\right)$. The other main peak of gypsum at $0.4280 \mathrm{~nm}(2 \theta=$ $20.74^{\circ}$ ) is very near to the peak of quartz at $0.4257 \mathrm{~nm}$ $\left(2 \theta=20.85^{\circ}\right)$, and, for this reason, it could not be taken into consideration (as was stated above). The peak intensities (in cps) of ettringite $\left(2 \theta=9.16^{\circ}\right)$ and gypsum $\left(2 \theta=11.59^{\circ}\right)$, taken from the X-ray diffractograms of the specimens (Figure 1), are presented in Table 4. According to literature data (18-20), different forms of $\mathrm{CaCO}_{3}$ (calcite, vaterite, aragonite, and amorphous) appear during $\mathrm{C}-\mathrm{S}-\mathrm{H}$ gel carbonation. Due to this, carbonation could not be estimated based on the intensities of the calcite peak, and hence, for this reason, the intensity of the main peak of calcite $\left(2 \theta=29.6^{\circ}\right)$ is not presented in Table 4.

As can be seen from Table 4, the intensities of the peak of gypsum increased with time for both mixtures, which indicated carbonation of these mixtures (3). The decrease of the peaks of ettringite with time in the first mixture also 


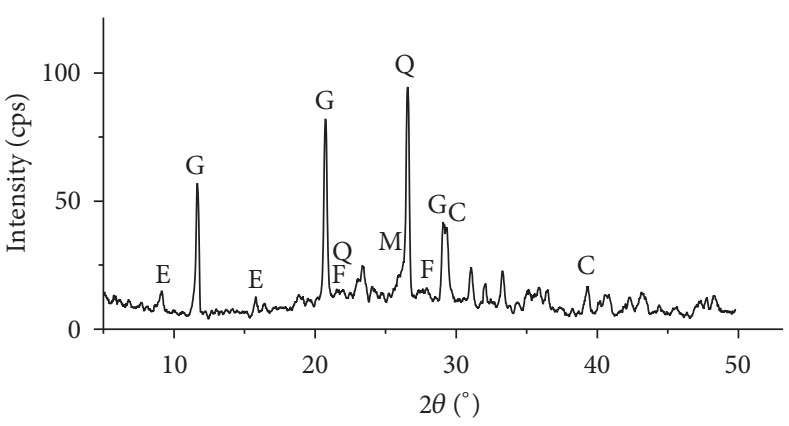

(a) FA consisted of coarser particles $(<1.651 \mathrm{~mm})$, after 7 days

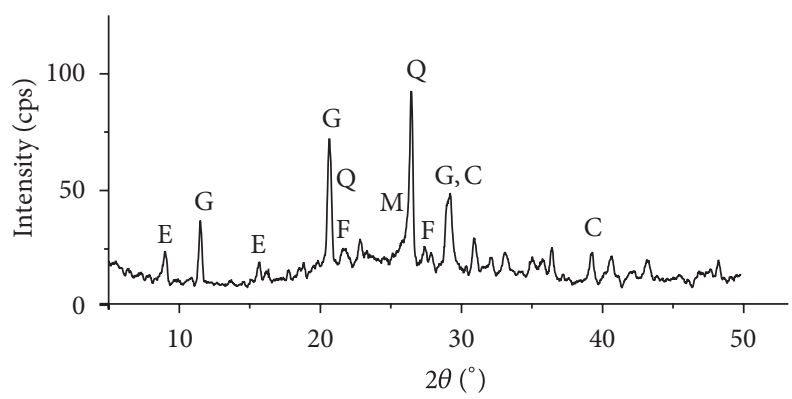

(c) FA consisted of smaller particles $(<0.42 \mathrm{~mm})$, after 7 days

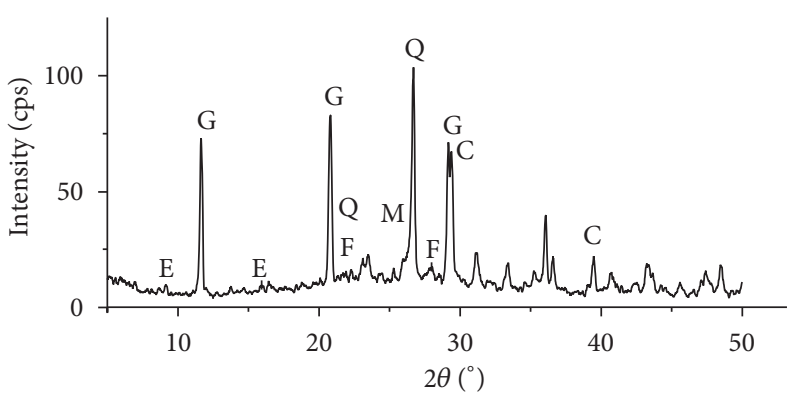

(b) FA consisted of coarser particles $(<1.651 \mathrm{~mm})$, after 28 days

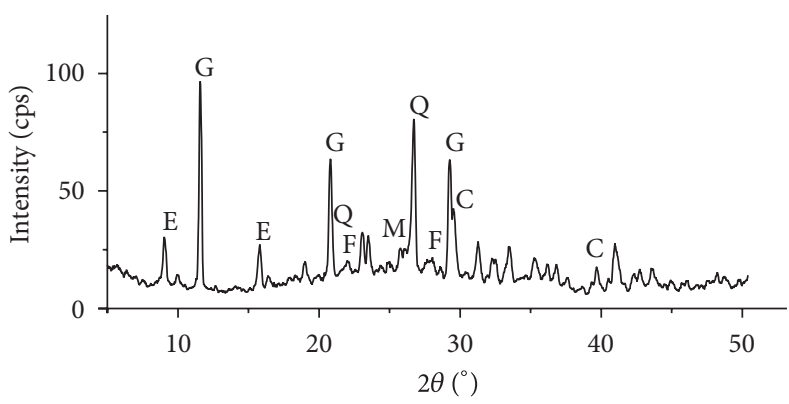

$\begin{array}{ll}\text { Q: quartz } & \text { E: ettringite } \\ \text { M: mullite } & \text { G: gypsum } \\ \text { F: feldspar } & \text { C: calcite }\end{array}$

(d) FA consisted of smaller particles $(<0.42 \mathrm{~mm})$, after 28 days

FIGURE 1: XRD diffractograms of the mixture FA-PC-FGD gypsum-BA-W.

TABLE 4: The intensity of the peaks of ettringite and gypsum.

\begin{tabular}{lcccc}
\hline & & \multicolumn{2}{c}{ Intensity of peak (cps) } & \\
Mixture & & $\begin{array}{c}\text { Ettringite } \\
\left(2 \theta=9.16^{\circ}\right)\end{array}$ & & $\left(2 \theta=11.59^{\circ}\right)$ \\
& 7 days & 28 days & 7 days & 28 days \\
\hline FA $^{*}$-PC-FGD-gypsum-BA & 15.38 & 10.42 & 53.84 & 71.87 \\
FA $^{* *}$-PC-FGD gypsum-BA & 21.74 & 29.17 & 34.78 & 93.75 \\
\hline
\end{tabular}

FA composed of particles $<1.652 \mathrm{~mm}$

${ }^{* *}$ FA composed of particles $<0.42 \mathrm{~mm}$.

indicated to carbonation phenomena. The increase in the size of both the peak of ettringite and of gypsum with time for second mixture could be explained by the higher reactivity of the smaller FA particles. The higher reactivity of the smaller FA particles resulted in the formation of a larger content of both ettringite and gypsum.

The results of the leaching test (European Standard EN 12457), that is, the concentrations of the trace elements in the extracts of powdered specimens (determined by atomic absorption spectroscopy) are presented in Table 5. In addition, the Waste Acceptance Criteria (WAC) for granular wastes and the limit values for compliance with EN12457 test at $\mathrm{L} / \mathrm{S}=10$ are also included in this table.

The results showed that both mixtures could be considered as hazardous material regarding the leached amounts of $\mathrm{Cd}, \mathrm{Pb}, \mathrm{Ni}$, and $\mathrm{Sb}$.
Comparing the metal concentrations in the extracts of the pulverized hardened specimens $\left(\mathrm{S}_{1}\right.$ and $\left.\mathrm{S}_{2}\right)$ after 7 days with those after 28 days, a significant increase in the concentration of $\mathrm{Sb}$, moderate increases in $\mathrm{Ni}$ and $\mathrm{Cr}$, and minor increase in the Cd concentrations in the extracts of both specimens after 28 days were found (Table 5).

These results could be correlated with the results of the $\mathrm{X}$-ray analysis. The formation of ettringite by the hydration reaction (1), evidenced by X-ray analysis in the specimens after 7 days, can immobilise metal ions. The immobilisation is achieved by the substitution of $\mathrm{Ca}^{2+}, \mathrm{Al}^{3+}$, and $\mathrm{SO}_{4}{ }^{2-}$ ions in the ettringite crystal structures $\left(\mathrm{Ca}_{6} \mathrm{Al}_{2}\left(\mathrm{SO}_{4}\right)_{3}\right.$ $\left.(\mathrm{OH})_{12} \cdot 26 \mathrm{H}_{2} \mathrm{O}\right)$ by metal ions and metal oxyanions [16, 17]. The carbonation phenomena and decomposition of ettringite (3) in specimens after 28 days (confirmed by the augmentation of the content of gypsum, see Table 4) 
TABLE 5: Results of the batch leach test and regulatory limits for the determined elements.

\begin{tabular}{|c|c|c|c|c|c|c|c|}
\hline \multirow{2}{*}{ Specimen } & \multicolumn{7}{|c|}{ Leachate concentration $\left(\mathrm{mg} / \mathrm{dm}^{3}\right)$} \\
\hline & $\mathrm{Cu}$ & $\mathrm{Zn}$ & $\mathrm{Cd}$ & $\mathrm{Pb}$ & $\mathrm{Ni}$ & $\mathrm{Sb}$ & $\mathrm{Cr}$ \\
\hline $\mathrm{S}_{1}$ after 7 days & $<0.1$ & 0.4 & 0.5 & 5 & 1 & 3 & $<0.1$ \\
\hline $\mathrm{S}_{1}$ after 28 days & $<0.1$ & 0.1 & 0.6 & 4 & 3 & 19 & 0.5 \\
\hline $\mathrm{S}_{2}$ after 7 days & $<0.1$ & 0.4 & 0.4 & 6 & 1 & 3.4 & $<0.1$ \\
\hline $\mathrm{S}_{2}$ after 28 days & $<0.1$ & 0.5 & 0.5 & 6 & 2 & 22 & 0.3 \\
\hline \multirow[t]{4}{*}{ WAC } & & & react & s was & zard & & \\
\hline & 5 & 5 & 0.1 & 1 & 1 & 0.07 & 1 \\
\hline & \multicolumn{7}{|c|}{ Hazardous waste landfill } \\
\hline & 10 & 20 & 0.5 & 5 & 4 & 0.5 & 7 \\
\hline
\end{tabular}

$\mathrm{S}_{1}$ made from the mixture: $18.6 \%$ FA-6.2\% PC-6.2\% FGD gypsum-31\% BA-38\% W, FA composed of particles of $<1.652 \mathrm{~mm}$.

$\mathrm{S}_{2}$ made from the mixture: $18.6 \%$ FA-6.2\% PC-6.2\% FGD gypsum-31\% BA-38\% W, FA composed of particles of $<0.42 \mathrm{~mm}$.

TABLE 6: Water content and absorption of water of Proctor specimens.

\begin{tabular}{lcc}
\hline Specimen & Water content (\%) & Absorption of water (\%) \\
\hline $\mathrm{S}_{1}$ after 7 days & 33.09 & 33.59 \\
$\mathrm{~S}_{1}$ after 28 days & 37.01 & 29.95 \\
$\mathrm{~S}_{2}$ after 7 days & 35.09 & 35.89 \\
$\mathrm{~S}_{2}$ after 28 days & 40.99 & 30.41 \\
\hline
\end{tabular}

$\mathrm{S}_{1}$ cylindrical specimen made from the mixture: 18.6\% FA-6.2\% PC-6.2\% FGD gypsum-31\% BA-38\% W, FA composed of particles of $<1.652 \mathrm{~mm}$.

$\mathrm{S}_{2}$ cylindrical specimen made from the mixture: $18.6 \%$ FA-6.2\% PC-6.2\% FGD gypsum-31\% BA-38\% W, FA composed of particles of $<0.42 \mathrm{~mm}$.

favour the breakdown of the ettringite structure, which affects the leaching processes and the transfer of metal ions and oxyanions to the leachates.

The average values (of three determination) of water content and absorption of water of monolithic (noncrushed) cylindrical (Proctor) specimens, after 7 and 28 days, are presented in Table 6.

The result presented in Table 6 shows that the water content was higher, but the absorption of water lower after 28 days than after 7 days in both specimens. These results also confirmed the carbonation of the specimens. During carbonation, the ettringite decomposed with the release of a lot of water and, consequently, the specimens after 28 days had a greater content of water than those after 7 days. In addition, it is known $[18,19]$, that, during carbonation, the structural properties of the specimens improve, for example, their pore volume decreases which are associated with the deposit of the formed $\mathrm{CaCO}_{3}$. For this reason, the absorption of water by $S_{1}$ and $S_{2}$ (Table 6) was lower for the specimens after 28 days than for the specimens after 7 days.

\section{Conclusions}

(1) Regarding the compressive strength values, the mixture FA-PC-FGD gypsum-BA with the mass composition $3: 1: 1: 5$ satisfied the criteria for subbase layers for heavy and medium traffic load which were proposed by the Public Enterprise-Roads of Serbia.
(2) The examinations realised in this study indicated that carbonation reactions occurred in the mixtures FA, PC, FGD gypsum, BA, and W $(3: 1: 1: 5)$, in addition to hydration reactions. The results that confirmed this phenomenon were

(a) augmentation of the peaks at $0.7630 \mathrm{~nm}$ in the X-ray diffractograms of the specimens that could only be explained by the formation of gypsum as a new, second phase (different from starting FGD gypsum),

(b) considerable improvement of the compressive strength of the specimens in the period from 7 to 28 days (the compressive strength increased about two times), which could be related to $\mathrm{CaCO}_{3}$ formation during carbonation $\left(\mathrm{CaCO}_{3}\right.$ has a very low solubility and would contribute to a clogging of the pores and in this way improve the compressive strength),

(c) increase in the water content in the monolithic cylindrical specimens during the period from 7 to 28 days, which is very probably related to the release of high amounts of water during the reaction of ettringite carbonation (3),

(d) decrease in water absorption by the monolithic cylindrical specimens during the period from 7 to 28 days, which is very probably a consequence of the decrease in the pore volume caused 
by the formation of a $\mathrm{CaCO}_{3}$ deposit during carbonation, and

(e) augmentation of content of $\mathrm{Cd}, \mathrm{Cr}, \mathrm{Ni}$, and $\mathrm{Sb}$ in the extracts of the crushed hardening mixtures between 7 and 28 days provoked by the degradation of ettringite crystal structure in which these metal ions were incorporated.

(3) The presence of gypsum in both hardened mixtures may cause delayed ettringite formation and eventually cracking of them (so called internal sulphate attack) because of that long-term examination (longer than of 28 days) would be useful for future investigation.

(4) The sulphate ions that could be released by dissolution of gypsum in water and the high level of some metal ions $(\mathrm{Cd}, \mathrm{Pb}, \mathrm{Ni}$, and $\mathrm{Sb})$ in the extracts of the mixtures could provoke environmental inconvenience. As the mixtures prepared in this work are applicable only for the construction of a subbase layers, the leaching of metal and sulphate ions from them is not to be expected of importance because subbase layers have no direct contact with atmospheric precipitations.

However, it is difficult to predict environmental impact of possible contact with groundwater. This would depend on the permeability of layers above and under the subbase layers and on the $\mathrm{pH}$ of the groundwater ( $\mathrm{pH}$ of ground water can be both higher and lower than 7).

\section{References}

[1] O. E. Manz, "Coal fly ash: a retrospective and future look," Fuel, vol. 78, no. 2, pp. 133-136, 1999.

[2] E. Benavidez, C. Grasselli, and N. Quaranta, "Densification of ashes from a thermal power plant," Ceramics International, vol. 29, no. 1, pp. 61-68, 2003.

[3] M. J. McCarthy and R. K. Dhir, "Towards maximising the use of fly ash as a binder," Fuel, vol. 78, no. 2, pp. 121-132, 1999.

[4] C. Freidin and W. Motzafi-Haller, "Cementless building units based on oil shale and coal fly ash binder," Construction and Building Materials, vol. 13, no. 7, pp. 363-369, 1999.

[5] P. Asokan, M. Saxena, and S. R. Asolekar, "Coal combustion residues-environmental implications and recycling potentials," Resources, Conservation and Recycling, vol. 43, no. 3, pp. 239-262, 2005.

[6] M. Cheriaf, J. C. Rocha, and J. Péra, "Pozzolanic properties of pulverized coal combustion bottom ash," Cement and Concrete Research, vol. 29, no. 9, pp. 1387-1391, 1999.

[7] Y. Bai and P. A. M. Basheer, "Influence of furnace bottom ash on properties of concrete," Proceedings of the Institution of Civil Engineers, vol. 156, no. 1, pp. 85-92, 2003.

[8] C. S. Poon, S. C. Kou, L. Lam, and Z. S. Lin, "Activation of fly ash/cement systems using calcium sulfate anhydrite $\left(\mathrm{CaSO}_{4}\right)$," Cement and Concrete Research, vol. 31, no. 6, pp. 873-881, 2001.

[9] V. G. Papadakis, "Effect of fly ash on Portland cement systems: part I. Low-calcium fly ash," Cement and Concrete Research, vol. 29, no. 11, pp. 1727-1736, 1999.

[10] J. A. Gadsden, Infrared Spectra of Minerals and Related Inorganic Compounds, Butterworths, Chichester, UK, 1975.
[11] D. Jozić and J. Zelić, "The effect of fly ash on cement hydration in aqueous suspensions," Ceramics-Silikaty, vol. 50, no. 2, pp. 98-105, 2006.

[12] R. Holly, H. Peemoeller, M. Zhang, E. Reardon, and C. M. Hansson, "Magnetic resonance in situ study of tricalcium aluminate hydration in the presence of gypsum," Journal of the American Ceramic Society, vol. 89, no. 3, pp. 1022-1027, 2006.

[13] C. A. García-González, A. Hidalgo, C. Andrade et al., "Modification of composition and microstructure of Portland cement pastes as a result of natural and supercritical carbonation procedures," Industrial and Engineering Chemistry Research, vol. 45, no. 14, pp. 4985-4992, 2006.

[14] D. Chen, E. Sakai, M. Daimon, and Y. Ohba, "Carbonation of low heat portland cement paste precured in water for different time," Journal of University of Science and Technology Beijing, vol. 14, no. 2, pp. 178-184, 2007.

[15] M. Fernández Bertos, S. J. R. Simons, C. D. Hills, and P. J. Carey, "A review of accelerated carbonation technology in the treatment of cement-based materials and sequestration of $\mathrm{CO}_{2}$," Journal of Hazardous Materials, vol. 112, no. 3, pp. 193-205, 2004.

[16] M. Chrysochoou and D. Dermatas, "Evaluation of ettringite and hydrocalumite formation for heavy metal immobilization: literature review and experimental study," Journal of Hazardous Materials, vol. 136, no. 1, pp. 20-33, 2006.

[17] M. L. D. Gougar, B. E. Scheetz, and D. M. Roy, "Ettringite and C-S-H portland cement phases for waste ion immobilization: a review," Waste Management, vol. 16, no. 4, pp. 295-303, 1996.

[18] S. Valls and E. Vazquez, "Accelerated carbonatation of sewage sludge-cement-sand mortars and its environmental impact," Cement and Concrete Research, vol. 31, no. 9, pp. 1271-1276, 2001.

[19] B. Johannesson and P. Utgenannt, "Microstructural changes caused by carbonation of cement mortar," Cement and Concrete Research, vol. 31, no. 6, pp. 925-931, 2001. 

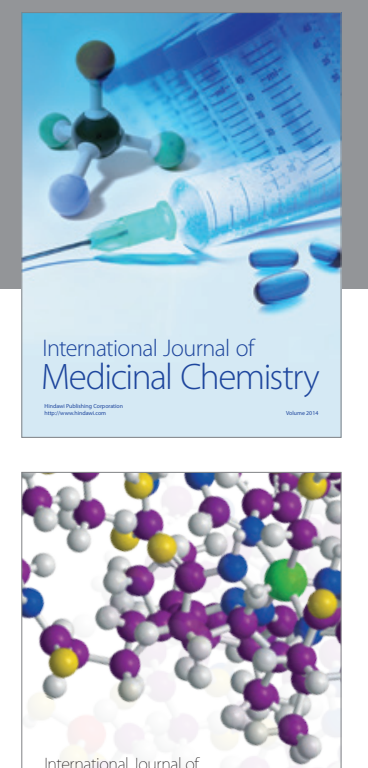

\section{Carbohydrate} Chemistry

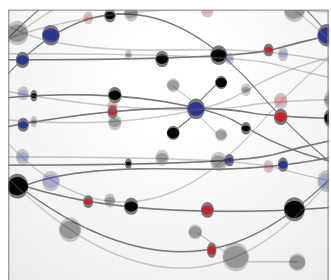

The Scientific World Journal
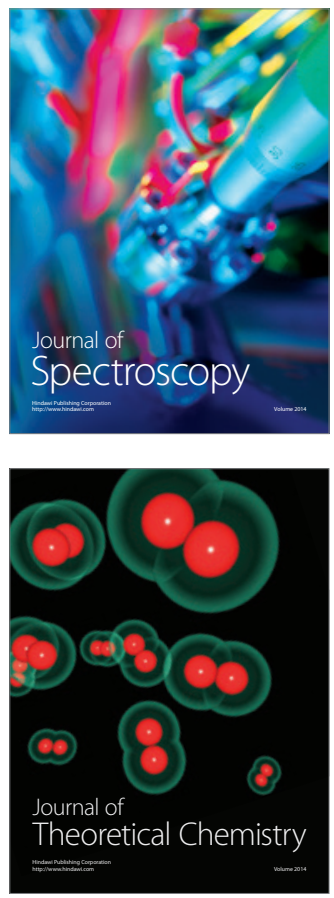
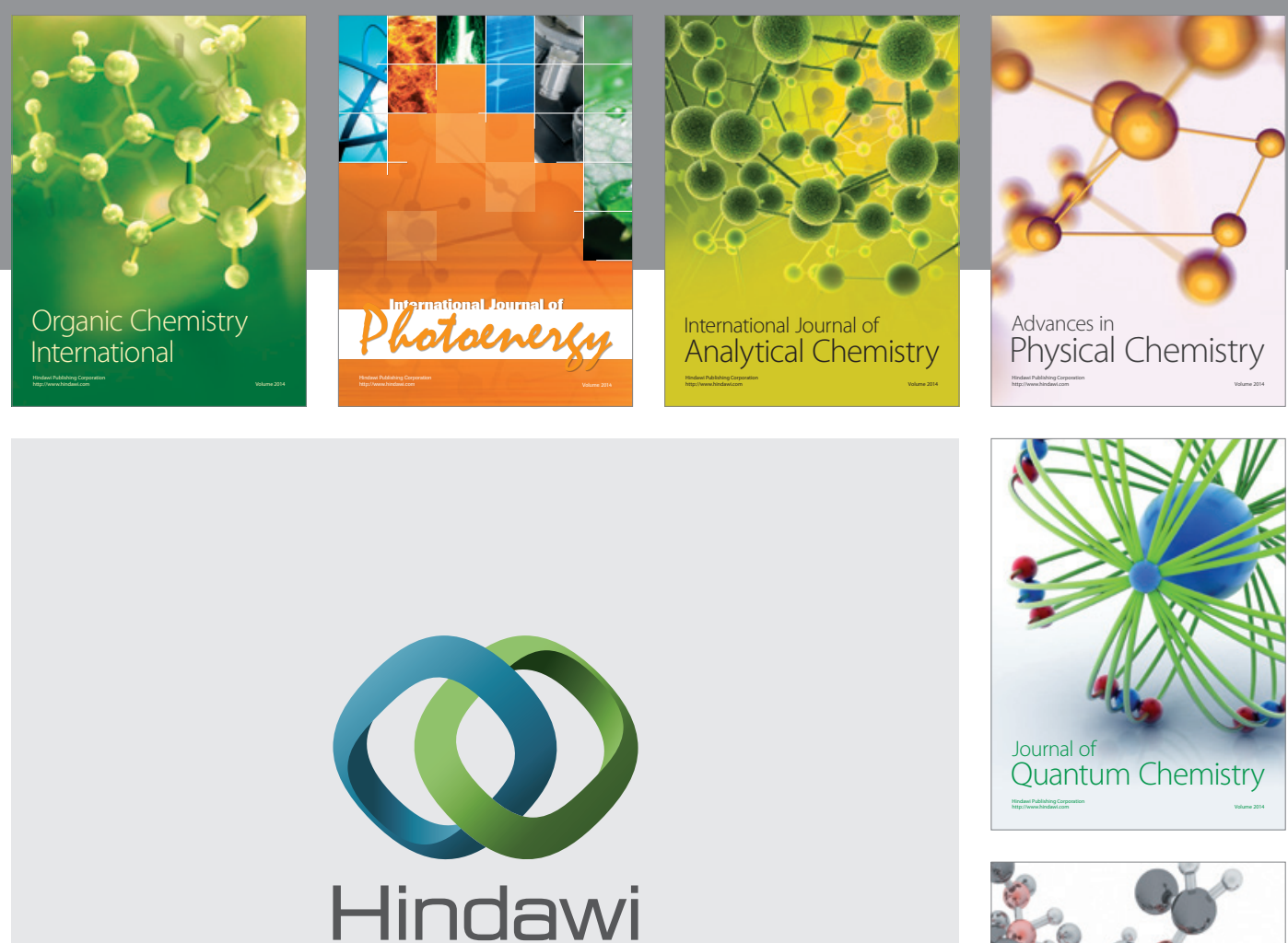

Submit your manuscripts at

http://www.hindawi.com

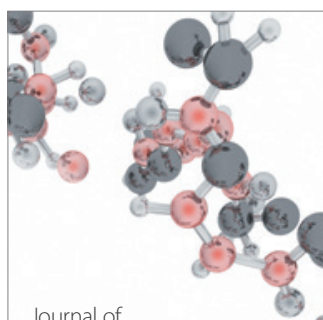

Analytical Methods

in Chemistry

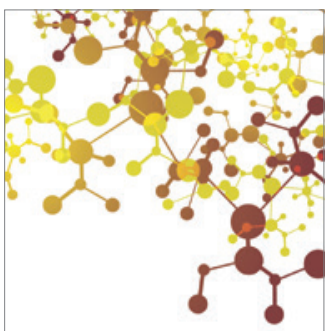

Journal of

Applied Chemistry

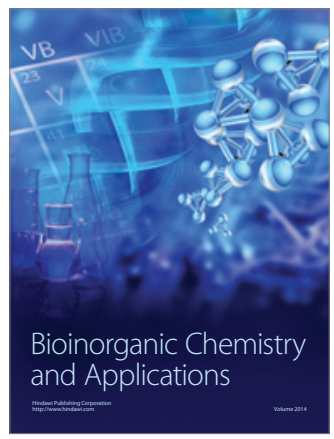

Inorganic Chemistry
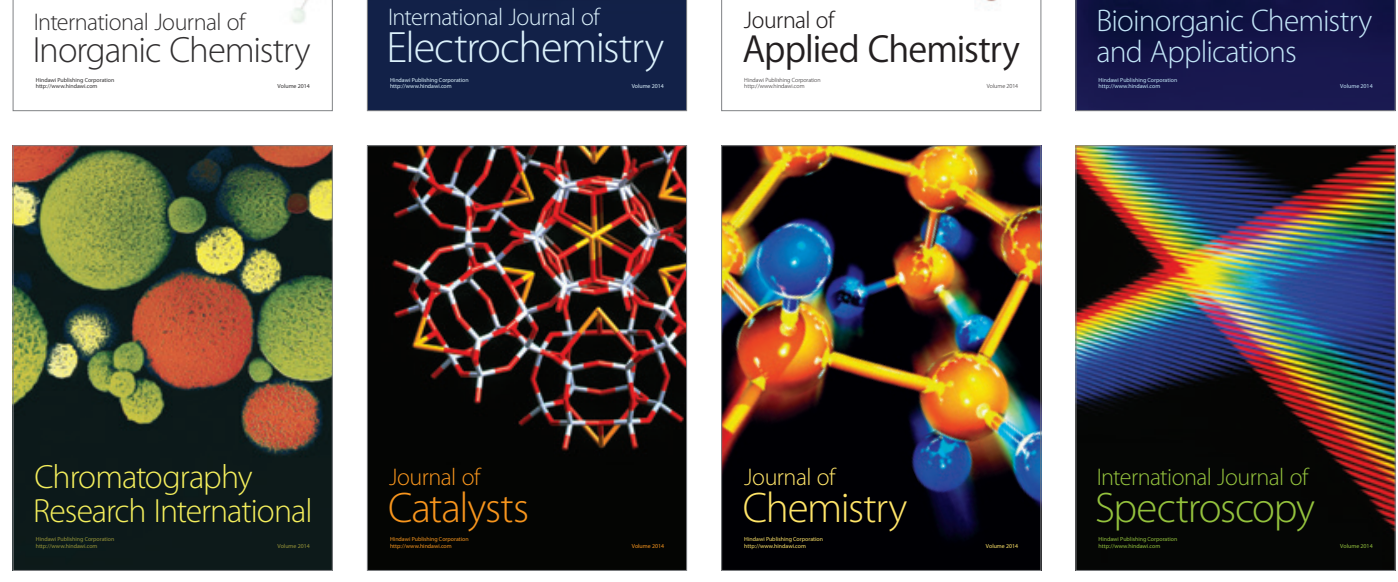